\title{
GESTÃo PÚBLICA DE RECURSOS HÍDRICOS: UMA ANÁLISE DA PERCEPČ̃̃o DE SEGMENTOS DA SOCIEDADE ORGANIZADA SOBRE A TRANSPOSIÇẪO DAS ÁGUAS DO RIO PARAÍBA DO SUL
}

\author{
PUBLIC WATER MANAGEMENT: AN ANALYSIS OF THE ORGANIZED SOCIETY \\ SEGMENTS' PERCEPTION OF THE TRANSPOSITION OF THE PARAIBA DO SUL \\ RIVER
}

\author{
GESTIÓN PÚBLICA DEL AGUA: UN ANÁLISIS DE LA PERCEPCIÓN DE LA \\ SOCIEDAD ORGANIZADA SOBRE LA TRANSPOSICIÓN DEL RÍO PARAIBA DO \\ $S U L$
}

José Ricardo Maia de Siqueira, Doutor em Engenharia de Produção pela COPPE/UFRJ. Professor da Universidade Federal do Rio de Janeiro. Endereço profissional: Programa de Pós

Graduação em Ciências Contábeis (PPGCC) da Universidade Federal do Rio de Janeiro (UFRJ), Av. Pasteur, 250, sala 250, Urca, Rio de Janeiro - RJ, CEP: 22.290-240. Fone (21) 3938-5262, email: jrms@facc.ufrj.br.

\section{RESUMO}

O rio Paraíba do Sul nasce da junção dos rios Paraibuna e Paraitinga, percorrendo $1.150 \mathrm{~km}$ dos estados de São Paulo, Minas Gerais e Rio de Janeiro, desaguando no Oceano Atlântico, na altura do município de São João da Barra. Há alguns anos, o governo do estado de São Paulo apresentou projeto para transposição de suas águas para atender à demanda crescente de recursos hídricos de regiões deste estado. Manifestações contrárias ao projeto se levantaram em função da preocupação com o seu impacto no Rio de Janeiro. O trabalho tem por objetivo analisar a percepção de segmentos da sociedade organizada do estado do Rio de Janeiro acerca do projeto de transposição das águas do rio Paraíba do Sul. Para atingir este objetivo, foram identificados segmentos organizados da sociedade civil fluminense e, através de um questionário semi-estruturado, foram captadas as percepções destes segmentos quanto ao impacto potencial do projeto paulista para a população do estado do Rio de Janeiro. Foi constatada a existência de uma preocupação com a redução na vazão do rio Paraíba do Sul, trazendo, em conseqüência, reveses para a população fluminense, que fica à jusante do projeto a ser implementado.

Palavras-Chave: Água; Gerenciamento de Recursos Hídricos; Rio Paraíba do Sul.

\section{ABSTRACT}

The Paraiba do Sul river is born from the union of Paraibuna and Paraitinga rivers, covering 1150 kilometers in São Paulo, Minas Gerais and Rio de Janeiro, emptying into the Atlantic Ocean at São João da Barra. Some years ago, the government of São Paulo presented a project to divert the flow of Paraíba do Sul river in order to meet the increasing demand of water in some regions of the state. Opposition movements against the project have arisen in the light of some concerns about its impact in Rio de Janeiro. The study aims to analyze the perception of segments of organized society in Rio de Janeiro about the project. To achieve this goal, it's identified some movement from the organized civil society in Rio de Janeiro and, through a semi-structured questionnaire, were captured on the perceptions of these

GєCont, v. 3, n. 2, Floriano-PI, Jul-Dez. 2016. 
segments to the potential impact of the project in the population of Rio de Janeiro. It has been found that there is a concern about the reduction of Paraíba do Sulriverflow, bringing, as a result, setbacks for the population of Rio de Janeiro, which lies downstream of the project to be implemented.

Keywords: Water; Water Management; Paraíba do Sul River.

\section{RESUMEN}

El río Paraíba do Sul se nace de la confluencia de los ríos Paraibuna y Paraitinga, recorriendo 1.150 kilômetros en los estados de Sao Paulo, Minas Gerais y Río de Janeiro, desembocando en el Océano Atlántico, en la ciudad de São João da Barra. Hace algunos años, el gobierno del estado de Sao Paulo presentó un proyecto para la transferencia del agua para satisfacer la creciente demanda de recursos hídricos en regiones de este estado. Las manifestaciones contra el proyecto surgieron debido a la preocupación por su impacto en Río de Janeiro. El trabajo tiene como objetivo analizar la percepción de los segmentos de la sociedad organizada del estado de Río de Janeiro sobre el proyecto de transferencia de las aguas del río Paraíba do Sul. Para lograr este objetivo, he sido identificado los segmentos organizados de la sociedad civil de Río de Janeiro y, a través de un cuestionario semiestructurado, fueron capturados la percepción de estos segmentos sobre el impacto potencial del proyecto de Sao Paulo para la población del estado de Río de Janeiro. Se ha encontrado la existencia de una preocupación por la reducción en el caudal del río Paraíba do Sul traer reveses a la población de Río de Janeiro, que se encuentra aguas abajo del proyecto a implementar.

Palabras-clave: Agua; Gestión de Recursos Hídricos; Río Paraiba do Sul.

\section{INTRODUÇÃO}

Rio Paraíba do Sul é o principal rio fluminense, banhando algumas das principais cidades do interior do estado do Rio de Janeiro, como Resende, Barra Mansa, Itatiaia e Campos dos Goytacazes, só para citar alguns exemplos.

Há alguns anos o estado de São Paulo apresentou projeto no sentido de resolver o problema crescente no suprimento de água de regiões do estado. Uma das opções apresentadas, trata-se da transposição das águas do rio Paraíba do Sul para atender a Macrometrópole Paulista que engloba três regiões metropolitanas - São Paulo, Campinas e Baixada Santista - mais regiões vizinhas e as macrorregiões do Vale do Paraíba e de Sorocaba. Projeto este que se iniciou frente a crise hídrica do sudeste.

Devido à importância do Paraíba do Sul para o estado fluminense, se levantou no Rio de Janeiro uma série de manifestações contrárias ao projeto, em função dos impactos potenciais que tal projeto terá no estado, que fica à jusante em relação ao estado paulista. Este trabalho tem por objetivo analisar a percepção de segmentos da sociedade organizada do estado do Rio de Janeiro, acerca do projeto de transposição das águas do rio Paraíba do Sul para atendimento às demandas do estado de São Paulo.

\section{FUNDAMENTAÇÃO TEÓRICA}

\subsection{GESTÃO DE RECURSOS HÍDRICOS: O Impacto da Atividade Humana}

O volume de água doce disponível para consumo é bastante restrito. Mais de $2 / 3$ da superfície do globo terrestre é coberto por água. A água salgada representa $97 \%$ do total e,

GєCont, v. 3, n. 2, Floriano-PI, Jul-Dez. 2016. 
consequentemente, os outros 3\% representam o volume de água doce, sendo que apenas 0,6\% são águas superficiais (FORNARI, 2001, p. 17).

Para agravar a situação, as reservas de água doce apresentam distribuição irregular ao redor do globo, existindo regiões com baixíssimo índice pluviométrico, como extensões do deserto do Saara, que podem ficar vários anos sem receber qualquer chuva (PHILLIPS, 2010).

Este recurso tão vital tem que satisfazer três grandes categorias de uso: o doméstico (higiene eingestão), agricultura e produção industrial e energética. Apesar da grande relevância do recurso, as perspectivas não se mostram muito favoráveis. O volume de água disponível deverá cair para $4.800 \mathrm{~m}^{3} /$ habitante em 2025, quando já foi de $6.800 \mathrm{em} 2005$. Enquanto na atualidade se tem cerca de 1,7 bilhão de pessoas afetadas pela escassez de água, se espera que esse número suba para 2,5 bilhões em 2025, atingindo inclusive grandes países como China e Índia (KERGOMARD, 2012).

A escassez de água pode ser um dos principais motivos para conflitos armados entre povos. Em regiões com crescimento populacional, redução dos recursos hídricos e instabilidade governamental, a ocorrência de guerras é uma possibilidade bem real. Há, inclusive, interpretações de que a tomada das Colinas de Golã durante a Guerra dos Seis Dias, ocorrida em 1967, teve como maior motivação mais a captura dos recursos hídricos lá existentes do que as alegadas razões de segurança (RODRIGUES, 2016).

Tendo esse cenário como pano de fundo, pode-se dizer que a América Latina é uma região que se destaca por seus recursos hídricos. Com $12 \%$ da superfície terrestre e $6 \%$ da população mundial, ela recebe um pouco menos de $30 \%$ das chuvas que caem sobre o planeta. Abriga também as duas maiores bacias hidrográficas do mundo: a Amazônica e a do rio da Prata. Brasil, Venezuela, Bolívia, Argentina, Colômbia e Chile são considerados países ricos em recursos hídricos por se encontrarem na faixa entre 10.000 e $100.000 \mathrm{~m}^{3} /$ pessoa/ano; enquanto a Guiana Francesa é classificada como muito rica, por estar acima de 100.000 $\mathrm{m}^{3}$ /pessoa/ano (PORTO-GONÇALVES, 2006).

A riqueza hídrica da América Latina se estende ao seu subsolo, que abriga uma das maiores reservas de água doce subterrânea do globo (o Aquífero Guarani), com 1,2 milhão de $\mathrm{km}^{2}, 70 \%$ dos quais em território brasileiro, abrangendo os estados de Goiás, Mato Grosso, Mato Grosso do Sul, Minas Gerais, Paraná, Rio Grande do Sul, Santa Catarina e São Paulo (FORNARI, 2001, p. 26-27).

A existência de tal riqueza, vem suscitando debates sobre a gestão compartilhada de águas internacionais, que, apesar de ter avançado muito no tocante a águas superficiais, ainda apresenta análises escassas em relação a águas subterrâneas. Na verdade, ainda paira muitas dúvidas sobre a distribuição do aqüífero, não se tendo certeza se a existência de rochas vulcânicas não porosas permite a comunicação entre vários corpos d'água, o que levanta dúvidas sobre a aplicabilidade da gestão compartilhada e traz preocupações quanto à contaminação e ao esgotamento dos recursos hídricos, por gerenciamento inadequado (RIBEIRO, 2008).

Estudo recente demonstra preocupação com o gerenciamento das águas do aqüífero na região de Ribeirão Preto, onde, com uma exploração hídrica equivalente a treze vezes a recarga da chuva, se apresentou uma redução nos níveis das águas da ordem de 60 metros na porção urbana. Além disso, constatou-se a impermeabilização da área de recarga pela expansão da mancha urbana e a existência de focos de contaminação diversos, oriundos de cemitérios, favelas, agrotóxicos usados nas plantações de cana-de-açúcar e vinhoto, entre outros. Infelizmente o poder público não tem adotado providências para a proteção do aqüífero, em função, notadamente, de interesses relacionados às atividades econômicas da região (VILLAR; RIBEIRO, 2009).

Os recursos hídricos têm sofrido diversas ameaças, dentre as quais se destacam o desflorestamento. A relação entre florestas e o ciclo da água já foi percebido pelo ser humano

GєCont, v. 3, n. 2, Floriano-PI, Jul-Dez. 2016. 
desde a antiguidade. Platão já fizera alusão ao papel das florestas na regulação dos sistemas hídricos. Apesar de muitos conceitos do passado se mostrassem errados, como a crença que a água nascia das raízes das árvores, a influência das grandes florestas sobre a circulação da água e os índices pluviométricos é inegável (LIEUTAGHI, 2012).

Esta relação entre a existência das florestas e o ciclo da água aparece no nascimento da crítica ambiental brasileira durante a transição entre os séculos XVIII e XIX na figura da teoria do dessecamento, que afirmava que as matas primárias tinham um efeito benéfico sobre o clima da região, fazendo com que as chuvas nasçam e caiam sobre o solo, desenvolvendo o cultivo e a criação de animais e trazendo prosperidade às populações (PÁDUA, 2002).

Atualmente a relação entre floresta e ciclo hídrico é melhor compreendida. Quando ocorre as precipitações, a copa das árvores amortece o impacto das gotas, retirando sua energia, que escorrem por folhas e galhos, alcançando suavemente o solo. A camada orgânica sobre a superfície, composta por folhas e galhos mortos, funciona como uma esponja, que absorve a água, fazendo-a infiltrar no solo e permitindo que o excesso escorra gradualmente formando córregos e rios. Nos períodos mais secos a umidade ainda existente é liberada, permitindo a perenidade dos rios. A transpiração das florestas libera umidade na atmosfera e mantém o equilíbrio hídrico regional e global (FUJIHARA et al., 2009).

Para as bacias hidrográficas um tipo de cobertura vegetal é de extrema importância, são as chamadas matas ciliares que, ao envolver os rios, além de ajudar o solo a reter água, ajuda a prevenir alagamentos, através do retardamento da chegada à calha do fluxo pluvial e da redução do problema de assoreamento (SALGADO, 2012).

Apesar da importância das florestas para o ciclo hídrico, a humanidade não cuidou adequadamente de suas florestas ao longo dos séculos. A madeira foi usada em habitações, construções diversas e até mesmo na cobertura de leitos de estradas. O poderio dos povos da antiguidade era medido pela forças navais e fenícios, romanos e vikings construíram grandes frotas. Uma única batalha onde a frota britânica arrasou a invencível armada envolveu centenas de enormes navios de madeira. As florestas europeias mostraram sua finitude após séculos de exploração. Este padrão de comportamento se repetiu na América do Norte. Quando da chegada dos colonos europeus, a região a leste do Mississipi tinha $70 \%$ das suas terras cobertas por florestas. No final do século XIX as matas cobriam apenas cerca de $25 \%$ do território (POLLACK, 2011).

$\mathrm{Na}$ atualidade o Brasil também não tem mostrado apreço por suas matas. Dados da FAO - Food and Agriculture Organization da ONU - demonstram que Brasil e Indonésia lideram o rol das nações que mais desmatam, seguidos por Sudão, Myanmar, Zâmbia, Tanzânia, Nigéria, República Democrática do Congo, Zimbábue e Venezuela. O Brasil lidera com considerável folga, sendo sozinho responsável por $48 \%$ do desmatamento mundial, contribuindo enormemente para que a América Latina alcance essa nada invejável liderança, seguida de perto pela África. A principal causa do desflorestamento na América Latina é a agricultura em larga escala, o que já levou à perda de $20 \%$ da floresta amazônica - embora o governo brasileiro reconheça apenas $17 \%$ de perda (GORE, 2009).

A atividade econômica tem sido um fator de grande impacto sobre a gestão de recursos hídricos. Esta é a realidade da América Latina que vê a demanda por água incrementar desde os anos 70, através da transferência, por parte de grandes corporações multinacionais, de plantas industriais consumidoras de água para a América Latina. Além disso, os recursos hídricos da região têm sofrido com a contaminação de químicos sintéticos e pesticidas entre outros focos possíveis (PORTO-GONÇALVES, 2006).

A questão hídrica vem preocupando as organizações empresariais. Em pesquisa sobre gestão e governança corporativa em relação às mudanças climáticas,dentre seis segmentos econômicos investigados, cinco apontaram entre os três maiores riscos reportados, questões envolvendo o impacto do ciclo hídrico nas operações organizacionais (CDP, 2014). 
Enquanto algumas empresas se preocupam com o impacto da escassez hídrica em seus negócios, outras enxergam a falta de água como uma oportunidade. Nasser (2016) vê com certa preocupação a transformação da água em commodity, uma vez que o poder corporativo cresceu enormemente ao longo dos anos, na atualidade algumas empresas vêm atuando tanto no Brasil, quanto na Ásia, Europa ou África, ou seja, não limitam sua atuação dentro de um único país. Resumindo, tem-se hoje cinco ou seis corporações mundiais em processo de substituição dos estados nacionais no gerenciamento deste recurso vital à vida.

A agricultura é, dentre as atividades humanas, aquela que mais exerce pressão sobre o consumo da água. A agricultura surgiu no Oriente Médio há cerca de 12.000 anos - e também desenvolveu-se de forma independente na China por volta de 8.000 a.C. e na América ao redor de 3.000 a.C. - e apesar de ter exercido um papel-chave na sedentarização do homem e no desenvolvimento das civilizações, causou graves problemas ecológicos ao longo dos anos (THEOHARIS, 2014).

No Brasil, onde se consome $986,4 \mathrm{~m}^{3} / \mathrm{s}$ de água, somente a irrigação absorve $69 \%$ do total, sendo de longe o maior consumo. Em um segundo lugar distante encontra-se o consumo animal, com $12 \%$, seguido pelo consumo urbano (10\%), industrial (7\%) e, por fim o consumo rural, absorvendo parcos $2 \%$ (NIEMEYER, 2012).

Obviamente que este não é um problema exclusivo da América Latina, mas sim com alcance global, que encontra no Mar de Aral um caso emblemático do impacto negativo da atividade econômica.

\subsection{O CASO DO MAR DE ARAL}

O mar de Aral é uma grande massa de água que encontra-se na região da Ásia Central entre o Uzbequistão e o Cazaquistão e já foi considerado, até os anos de 1960,um dos maiores lagos existentes no mundo(OECO, 2010).

Este lago, situado a cerca de 600 quilômetros do Mar Cáspio, costumava ter mais de 1.100 ilhas, vindo daí sua denominação, já que Aral significa ilha. Cobria, até 1960, uma área de 66.000 quilômetros quadrados, alimentado por dois grandes rios: o Sirdaria na parte norte e o Amudaria na região sul. Este último, considerado o maior rio da região nasce nas montanhas de Kunlun e corta o Kirguizistão, Tadjiquistão, Uzbequistão, Turkmenistão e retorna ao Uzbequistão antes de desaguar no mar de Aral. Já o Sirdaria nasce no maciço Tien Shan no Kirguizistão e passa pelo Tadjiquistão, Uzbequistão, Cazaquistão. Estes dois rios foram sempre a base da estabilidade do nível do Mar de Aral (KUMAR, 2010).

Uma intensa atividade piscatória se desenvolvia no lago, que possuía uma grande variedade de espécies - incluindo o conhecido esturjão de Aral - que alimentava uma indústria local com capturas anuais que superavam 40 mil toneladas. Os deltas formavam lagos menores e alagadiços com enorme riqueza biológica. No entorno cresceu uma cerrada floresta de juncos e havia vastas populações de antílopes, lobos, raposas, javalis, perus, patos e gansos (KUMAR, 2010).

No início dos anos 1960, a extinta União Soviética, elaborou um arrojado plano visando sua auto-suficiência em algodão e o crescimento de sua produção de arroz. Para isto foram construídas grandes barragens e um canal de irrigação central com 850 milhas de extensão acoplado a um sistema de canais, que começaram a captar as águas dos dois rios que alimentavam o Mar de Aral. Com isso, o volume de água evaporada não era mais reposta pelo caudal dos dois grandes rios e o mar de Aral começou a encolher (OREXCA, 2010).

O fenômeno surpreendeu os moradores de Muynak, uma movimentada cidade pesqueira, que lutaram contra os efeitos do retrocesso das águas através da construção de canais que permitiam a chegada dos barcos ao seu porto. Infelizmente este não era o único problema. Com a redução do volume de água, o lago, situado sobre uma extensa planície de 
solo salino, começou a apresentar uma salinidade crescente. Além disso, as vastas áreas de monocultura no Uzbequistão demandaram grandes quantidades de pesticida. $\mathrm{O}$ crescimento da salinidade e da toxicidade da água exterminou as vinte espécies identificadas de peixes da região, bem como a cidade de Muynak, que hoje é uma cidade fantasma, localizada a mais de 100 quilômetros do mar e açoitada por ventos com uma poeira tóxica que levanta do solo ressequido e contaminado por pesticidas químicos. O nível do mar de Aral já reduziu mais de $60 \%$ em relação ao apresentado no início dos anos 1960 (OREXCA, 2010).

Há uma forte mobilização internacional pela salvação do mar de Aral. Uma das saídas que vêm sendo levantadas é o reconhecimento da região como uma Herança Natural e Cultural Mundial com o objetivo de chamar a atenção da comunidade internacional e impedir seu desaparecimento, considerado como um dos piores desastres ambientais já causados pelo homem (GLANTZ; FIGUEROA, 1997).

Espera-se que desta história fique, pelo menos,o aprendizado das conseqüências nefastas que podem ocorrer de um gerenciamento precário dos recursos hídricos. O caso do Mar de Aral torna-se assim um caso emblemático para os mais distintos povos do planeta, bem como para as gerações futuras.

\subsection{O RIO PARAÍBA DO SUL}

O rio Paraíba do Sul nasce da junção dos rios Paraibuna e Paraitinga, percorrendo $1.150 \mathrm{~km}$ dos estados de São Paulo, Minas Gerais e Rio de Janeiro, desaguando no Oceano Atlântico, na altura do município de São João da Barra (COELHO, 2012).

A bacia hidrográfica do rio Paraíba do Sul abrange 184 municípios, sendo: 57 no estado do Rio de Janeiro, 88 em Minas Gerais e 39 em São Paulo. Trata-se de uma das regiões mais industrializadas do Brasil, contando com 8.500 indústrias instaladas e respondendo por $12 \%$ do Produto Interno Bruto do país. A população atendida pela bacia é de cerca de 5,5 milhões de habitantes, sendo: 2,4 milhões de pessoas no Rio de Janeiro, 1,3 milhão no estado de Minas Gerais e 1,8 milhão em São Paulo (AGEVAP, 2009, p. 20).

Devido ao volume significativo de pessoas atendidas pela bacia do rio Paraíba do Sul, preocupação especial tem sido despendida para o controle das cheias. Desde 1977 são elaborados os Planos Anuais de Controle de Cheias, que se baseiam em um sistema de volumes de espera, ou seja, volumes vazios separados nos reservatórios para atender a picos de cheia. Apesar dos cuidados, as chuvas que caíram no final de 2009 e início de 2010, levaram a 11 mortes e mais de oito mil pessoas desalojadas e desabrigadas por toda a bacia (CEIVAP, 2010, p. 9-10).

O Paraíba do Sul vem sofrendo de longa data com a ação humana, sendo o repositório de esgotos domésticos e industriais. Estudos realizados pela UFRJ revelaram anomalias severas em peixes que vivem próximas aos sedimentos no fundo do rio Paraíba do Sul. O cascudo é a maior vítima de resíduos tóxicos como o ascarel e o benzopireno, lançados pelas indústrias ao longo dos anos. Dos espécimes de cascudos coletados abaixo da Companhia Siderúrgica Nacional, 35,6\% apresentaram deformações graves (BRANDÃO, 2004, p. 16).

Candiani et al. (2013) ao analisar a instalação de uma pequena central hidrelétrica (PCH) na altura do município de Queluz em São Paulo, enxergaram com preocupação a falta de necessidade de elaboração de EIA-RIMA para as PCHs, uma vez que todo empreendimento traz algum nível de impacto ambiental e a construção de várias destas unidades podem fazer com que os impactos sejam muito significativos. O caso de Queluz torna-se emblemático, pois próximo a essa hidrelétrica existe a $\mathrm{PCH}$ de Lavrinhas, um município vizinho localizado na bacia do rio Paraíba do Sul. No caso da unidade de Queluz foi percebida a falta de um amplo debate antecedendo sua implantação, o que resultou na falta de informação sobre o empreendimento por parte da comunidade afetada. 
Há que se destacar, contudo, que existem projetos que trazem impactos positivos à bacia hidrográfica do rio Paraíba do Sul. É o caso do ocorrido na região da Microbacia do ribeirão dos Macacos, tributário do rio Paraíba do Sul, que se localiza nos municípios de Guaratinguetá e Lorena. Nesta região o uso do solo tem uma predominância rural e foi alvo de implantação, por parte do Instituto Oikos de Agroecologia, de um projeto envolvendo práticas sustentáveis que englobou a instalação de fossas sépticas, criação de chorumeiras, construção de bebedouros para o gado e recuperação da Área de Preservação Permanente, entre outras. Após a implementação do projeto foi observada uma tendência de melhoria dos parâmetros de qualidade da água do Ribeirão dos Macacos (ALVARENGA et al., 2012).

Recentemente um projeto envolvendo o rio Paraíba do Sul vem despertando preocupação. Trata-se do projeto de transposição das águas do rio para atendimento das demandas hídricas da Macrometrópole Paulista. O projeto já despertou preocupações do Comitê das Bacias Hidrográficas do Rio Paraíba do Sul que pediu esclarecimentos e providências à Secretaria de Saneamento e Energia e à empresa envolvida no projeto sobre informações equivocadas existentes no relatório apresentado (CEIVAP, 2010a, p. 10).

O Rio Paraíba do Sul já foi objeto de uma transposição de águas há mais de meio século atrás, para atender à Light, uma concessionária de energia elétrica. A transposição marcou tão profundamente a ocupação socioeconômica da área da bacia, que mesmo se não houvesse mais a necessidade de geração de energia, o desvio das águas do Paraíba do Sul teria que continuar, devido às atuais demandas de água por parte da população, das atividades econômicas e, mesmo, para fins de manutenção do equilíbrio ambiental, resultante da disponibilidade hídrica criada pela transposição (MACEDO; PIMENTEL, 2010, p. 6).

A questão do Paraíba do Sul ganhou importância com a crise hídrica. Em 2014, embora o governo paulista se recusasse a reconhecer, houve racionamento de água em Campinas, interior e Grande São Paulo. No Rio de Janeiro a situação não era melhor, tendo falta de água em bairros da zona norte e oeste da capital fluminense (BAVA, 2014).

Contudo, a situação de escassez não deveria ser surpresa, pois há, pelo menos, uma década os planos regionais de recursos hídricos e técnicos da área já previam que a água disponível seria superada pelo consumo. Este processo foi potencializado pela implementação de projetos governamentais de grande porte, que atraíram mais população e geraram maior atividade econômica; desmatamento; crescimento do volume de esgotos industrial e doméstico e aumento do processo erosivo. A destinação de recursos para pagamento de dividendos a acionistas da empresa de saneamento em detrimento dos investimentos necessários não melhorou a situação, obviamente (MATTES; TAGNIN; PRATA, 2014).

Lutti (2014) reforça a idéia de que a crise hídrica de São Paulo era uma tragédia anunciada há décadas e chama a atenção para a omissão de funcionários ligados ao poder público, que falharam no alcance de metas deredução de perdas na distribuição da água - que chega a atingir $45 \%$ em cerca da metade da região metropolitana - e de tratamento de esgoto. Some-se a isso a incapacidade de encontrar alternativas visando reduzir a dependência do Sistema Cantareira, de adotar ações visando a recarga dos aquíferos e de direcionar recursos para melhorar a qualidade das águas dos mananciais, que são usados para pagar dividendos vultosos e campanhas publicitárias milionárias em um mercado pouco competitivo.

\section{METODOLOGIA}

Esta pesquisa se classifica, segundo a tipologia sugerida por Raupp e Beuren (2003) quanto aos objetivos como exploratória; quanto aos procedimentos ela é, simultaneamente, pesquisa bibliográficae pesquisa documental; e, quanto à abordagem do problema, ela é qualitativa. Ela é exploratória porque procura proporcionar maior conhecimento sobre o 
objeto de estudo, além de objetivar conseguir um novo enfoque sobre o assunto em questão (ANDRADE, 1995).

Quanto aos procedimentos ela é bibliográfica pois recorre ao conjunto de conhecimentos armazenados sobre o tema, esperando conseguir não uma simples repetição de opiniões expostas anteriormente, mas a construção de um arcabouço conceitual sobre o qual se desenvolverá o artigo (ANDRADE, 1995). É documental porque analisa fontes primárias, ou seja, o conjunto de materiais "ainda não elaborados, escritos ou não, que podem servir como fonte de informações para a pesquisa científica" (LAKATOS; MARCONI, 1992, p. 43).

É qualitativa pois esta pesquisa procura "descrever a complexidade de determinado problema, analisar a interação de certas variáveis, compreender e classificar processos dinâmicos vividos por grupos sociais" (RICHARDSON, 1999 apud RAUPP;BEUREN, 2003, p. 91).

Quanto às técnicas utilizadas, além da consulta à bibliografia e documentos, foi utilizada a observação e a entrevista formal, onde, segundo Martins (2006, p. 88), há "a organização de um roteiro de questões cujas respostas atendam ao objetivo específico de coletar dados para determinado assunto da pesquisa".

Para fins desta pesquisa foram entrevistadas seis pessoas, dois membros da diretoria de organizações não governamentais, dois dirigentes de associações empresariais, um diretor de uma agência e o membro de uma câmara municipal de um município sul fluminense - vide Quadro 1.

\section{Quadro 1- Relação de Entrevistados}

\begin{tabular}{|l|c|}
\hline \multicolumn{1}{|c|}{ Caracterização do Entrevistado } & Identificação no Texto \\
\hline Dirigente da Associação Empresarial Pró-Penedo & E01 \\
\hline $\begin{array}{l}\text { Membro da diretoria da ONG GEAN. Membro do COMAR - Conselho do } \\
\text { Meio Ambiente do Município de Resende. }\end{array}$ & $E 02$ \\
\hline $\begin{array}{l}\text { Membro da Câmara de Vereadores do Município de Resende. Membro do } \\
\text { Movimento Contra a Transposição do Rio Paraíba do Sul. }\end{array}$ & $E 03$ \\
\hline Diretor da Agência da Bacia do Rio Paraíba do Sul - AGEVAP. & $E 04$ \\
\hline Membro da diretoria da ONG Crescente Fértil & $E 05$ \\
\hline Dirigente da Câmara de Dirigentes Lojistas de Resende - CDL. & $E 06$ \\
\hline
\end{tabular}

Fonte: Elaborado pelo autor

Os depoimentos encontram-se relacionados aos entrevistados segundo a identificação constante na segunda coluna do Quadro 1, cabe destacar ainda que estes foram transcritos utilizando-se aspas e itálico, objetivando a pronta diferenciação das citações bibliográficas. A notação utilizada é a letra "E" - inicial da palavra entrevistado - seguida pela ordem de ocorrência das entrevistas. Visando obter a expressão mais original e genuína das declarações dos entrevistados foi mantido o tom coloquial e eventuais desvios do bom uso da língua nos relatos transcritos nesta pesquisa.

\section{ANÁLISE DOS RESULTADOS}

Este segmento do trabalho está subdividido em três tópicos que abordam a percepção dos entrevistados em relação a três aspectos: nível de conhecimento sobre o projeto, possíveis impactos do projeto sobre o estado do Rio de Janeiro e posicionamento em relação ao projeto.

\subsection{NÍVEL DE CONHECIMENTO SOBRE O PROJETO}

Dos seis entrevistados, cinco demonstraram ter conhecimento sobre o projeto de transposição das águas do rio Paraíba do Sul. E01, da Associação Empresarial Pró-Penedo, 
disse não ter conhecimento sobre o projeto paulista e foi categórica ao afirmar que tem a percepção de que "há um desconhecimento geral".

A afirmativa de E01 levanta uma questão interessante: até que ponto a população fluminense está informada sobre o projeto de transposição? A relevância deste questionamento é destacada pelo discurso de E02, que deixou claro que seu conhecimento sobre o projeto paulista era superficial, sinalizando que o Conselho do Meio Ambiente do Município de Resende (COMAR), não tem incluído a transposição das águas do rio Paraíba do Sul na sua pauta de discussões. Se os membros de um organismo voltado para questões ambientais aparentam não ter um conhecimento aprofundado sobre o tema em questão, o que se pode dizer do nível de informação da população em geral?

Dos seis entrevistados, cinco afirmaram que a população não está adequadamente informada. E02 credita parte da responsabilidade pela desinformação da população pela atuação precária da mídia. Segundo ele "a mídia tinha que estar mais entrosada nisto, tinha que estar mais atuante (...) e trazendo mais informações".

Apesar de reconhecer a inadequação do nível médio de informação da população, E04 destaca a existência de assimetrias no grau de conhecimento sobre o projeto na região. Para o dirigente da Agência da Bacia do Rio Paraíba do Sul (AGEVAP), a população tem mais ciência a respeito do projeto "em Volta Redonda, porque o bispo trouxe para si essa responsabilidade, ele envolveu muito mais a comunidade. Então está muito mais discutido, muito mais conhecido e os jornais dão mais ênfase". Ele acrescenta ainda que nesta cidade do Vale do Paraíba, há uma reunião mensal onde são chamadas autoridades e pessoas envolvidas com a questão da transposição para debater sobre o assunto e encaminhar demandas que emanam da comunidade.

E03 destoa um pouco dos demais entrevistados e declara que a população de Resende tem sido informada através da ação do Movimento Contra a Transposição do Rio Paraíba do Sul, que vem se manifestando através da imprensa.

E03 esteve à frente do que, provavelmente, pode ser considerado como a principal ação em Resende de estímulo ao debate sobre o projeto de transposição, uma audiência públicaque contou com a participação da CDL, igreja católica e o conselho de pastores da região e FIRJAN, entre outras entidades políticas, além de políticos fluminenses. Segundo E03, a audiência contou com "todos os movimentos da população".

É interessante destacar que com exceção de E01, dirigente da Associação Pró-Penedo localizada no município de Itatiaia, todos os entrevistados tiveram conhecimento da audiência pública realizada na cidade de Resende.

E04, no entanto, relativiza um pouco o impacto da audiência pública no nível de informação da população em geral ao questionar "na audiência pública foram quantas pessoas? Cem pessoas, cento e cinqüenta pessoas, duzentas pessoas? Não teve o efeito multiplicador". Todavia, o dirigente reconhece que se tratava de um grupo seleto, com "pessoas de peso: o prefeito, o secretário de meio ambiente, o deputado Noel de Carvalho (...) e todos os vereadores".

E05 também reconhece a importância da audiência pública e afirma que por conta dela e de algumas notícias "pode até haver uma idéia de que o projeto existe, mas não há certamente uma reflexão um pouco mais profunda do significado disto". Esta afirmativa caracteriza a visão de $E 05$ de que a população não se encontra suficientemente informada.

\subsection{IMPACTOS POTENCIAIS DO PROJETO}

A preocupação com a redução no nível de água do rio Paraíba do Sul, esteve presente na fala de todos os seis entrevistados, contudo, eles apresentaram diferentes níveis de elaboração no tocante aos possíveis desdobramentos da baixa da linha d'água do rio. 
E06 afirma que "os danos ambientais aqui para o municipio seriam de grande proporção", destacando uma preocupação de cunho ecológico presente na fala dos entrevistados.

Esta preocupação se deve, em grande parte, pela relevância, em vários aspectos, do rio para o estado do Rio de Janeiro. E04 é categórico ao afirmar que "o impacto no rio Paraíba do Sul é sentido por todo o estado do Rio de Janeiro (...). Ele é o rio mais importante do estado do Rio".

A preocupação ambiental encontra-se muito presente no discurso de E02 que demonstra preocupação com o impacto que a redução no nível do rio pode causar na fauna e flora ciliar. Ele destaca ainda preocupação com o nível de toxicidade das águas do rio, em função de uma menor diluição dos esgotos, tanto domiciliar quanto industrial. Preocupação esta que aparece também claramente no discurso de E05.

A menor diluição dos esgotos lançados no rio remete a uma discussão da qualidade da água do rio e seu impacto na captação de águas para consumo. A preocupação com o abastecimento de água encontra-se presente muito claramente no discurso de quatro dos seis entrevistados.

E04 destaca que "o rio Paraíba do Sul é extremamente importante. O Rio de Janeiro não tem outra fonte. Qual é a grande fonte de água do Rio de Janeiro? Se você mexer no rio Paraíba do Sul, você afeta a cidade do Rio de Janeiro diretamente".

A fala de E04 é extremamente importante pois destaca fato pouco conhecido por grande parte da população, o fornecimento de água aos cariocas é, em grande parte, função do rio Paraíba do Sul. O rio Guandu, pedra basilar no fornecimento de água da capital fluminense, tinha no passado um caudal pouco significativo, pelo menos não para os padrões atuais de demanda de uma cidade com o porte e a importância do Rio de Janeiro e, como destaca Macedo e Pimentel (2010, p. 6) passou a ser alimentado por uma transposição das águas do rio Paraíba do Sul realizada há mais de meio século atrás. Nota-se, portanto, que mesmo a capital do estado pode ter seu abastecimento afetado se a redução no volume de águas do rio for significativa.

Além disso, muitas das principais cidades do interior tem parte significativa de sua vida socioeconômica diretamente associada ao rio Paraíba do Sul. Resende, Barra Mansa, Volta Redonda (que recebe seu nome em função de um quase círculo formado pelo curso do rio), Três Rios e Campos, são apenas algumas das cidades banhadas por este importante curso de água.

É importante destacar, que a transposição de águas para o Guandu, segundo E04, já trouxe uma redução acentuada no volume de água do Paraíba do Sul, que muitas vezes se assemelha a um "riachão", só recuperando seu porte depois de receber as águas de seus afluentes mineiros.

Para E02 fica claro que a potencial piora na qualidade da água trará ainda outras consequiências. Não havendo inviabilização de captação para fins de abastecimento devido à menor diluição dos poluentes, fica clara a necessidade de realização de maior esforço para tratamento da água, com o conseqüente aumento no sacrifício econômico por parte dos municípios. Recursos estes que poderiam estar sendo direcionados para a melhoria do bem estar da população, através de investimentos em saúde e educação, só para citar dois exemplos.

Além disso, ainda segundo E02, ficaria sempre uma preocupação subjacente quanto à real eficácia deste maior esforço no tratamento da água.

Dois entrevistados - E02 e E06 - demonstraram explicitamente suas preocupações quanto à possibilidade de haver prejuízo na capacidade de geração de energia, já que o Paraíba do Sul abriga diversas usinas hidroelétricas de porte considerável - como a do Funil 
na região de Resende e Itatiaia - e outras menores - como aquelas situadas próximas ao município paulista de Queluz, perto da divisa com o Rio de Janeiro, por exemplo.

Obviamente que problemas de geração acarretam impactos econômicos negativos, preocupação externada explicitamente por E04 e também por E05, que enxerga uma redução no potencial turístico do Rio de Janeiro, pela impossibilidade de práticas de lazer associadas aos cursos de água como o rafting, por exemplo.

Para E05 o principal impacto de tal projeto é a disseminação da cultura de má gestão de recursos hídricos e os abusos que dela pode vir.

\subsection{POSIÇÃO EM RELAÇÃO AO PROJETO}

Dos seis entrevistados, cinco mostraram-se contra o projeto de transposição do rio Paraíba do Sul. E02 foi o único entrevistado que afirmou necessitar de maior volume de informações para se posicionar, embora destaque que a princípio tem uma inclinação negativa em relação ao projeto.

E05 se posiciona contrariamente pelo princípio que se encontra por trás do projeto, afirma ele que "é um recurso muito cômodo para uma grande cidade, na medida que cresce desordenadamente, ir buscando os recursos vizinhos para conseguir fazer frente ao seu crescimento".

E04 engrossa o coro na linha do crescimento desordenado, chamando atenção para um dado importante: "a Sabesp trabalha com perda de 40\% ou mais". O discurso de E03 não é muito distante ao afirmar que "agora, neste momento que São Paulo (...) não fez o dever de casa de cuidar de seus rios, agora eles vem aqui e querem fazer uma transposição para abastecer a metrópole de São Paulo".

E03 toca em um ponto importante, talvez uma das opções de lidar com o problema de desabastecimento esteja no adequado gerenciamento dos rios paulistas. E04 aponta o Tietê como uma das possíveis soluções e coloca um questionamento em forma de desafio, será que as universidades paulistas, como a USP e a Unicamp, "não têm competência técnica para resolver o problema do rio Tietê? Tem, lógico que tem. E por que não resolve? Porque falta vontade política. (...) São Paulo tem os mananciais dentro dele e não resolve por problema político. Não é problema técnico”.

E05 também sinaliza pela solução técnica. Para ele o problema "deve ser superado por meio de tecnologia, por meio de racionalização do uso, como captação de água de chuva, reaproveitamento e controle do crescimento urbano".

O discurso de E04 também passa pelo controle do crescimento urbano ao declarar de forma crítica que "infelizmente São Paulo ainda está pensando como a velha Roma há mais de 2.000 anos atrás. Trazer tudo para a capital, trazer tudo para o centro". Ele arremata seu discurso com a proposição de um esforço de desconcentração da administração pública, traçando um paralelo com a criação de Brasília em meados do século passado.

Para E05, se for feita uma comparação de "São Paulo com muitos outros lugares, com muitos outros países, que são desertos praticamente, na verdade tem muita água. O que existe é uma cultura de desperdício". Posição que é corroborada por E04 ao afirmar que "aqui no Brasil agente esbanja água e não quer pagar".

Para E03 este posicionamento de não aceitação do projeto se estende pela população e arremata afirmando que "a gente observa que existe uma grande preocupação da população quanto a esta transposição". Segundo ele, esta preocupação se estende por todo o Vale do Paraíba, o que pode ser constatado pelos movimentos contra a transposição nas cidades de Barra Mansa, Volta Redonda, São José dos Campos e Taubaté, só para citar alguns exemplos.

E04 afirma peremptoriamente que uma das piores maneiras de lidar com a falta de água é a transposição, "porque quando chegar em 2025 vai acabar a água, e aí?".

GєCont, v. 3, n. 2, Floriano-PI, Jul-Dez. 2016. 


\section{CONSIDERAÇÕES FINAIS}

O Brasil é, em termos absolutos, o país com a maior disponibilidade de recursos hídricos do mundo. Abriga dentro de seu território a maior bacia hidrográfica do planeta - a Amazônica - e conta com diversos rios de grande porte, como o Paraná e o São Francisco, só para citar dois exemplos. Tem dentro de suas fronteiras a maior reserva mundial de água doce subterrânea: o Aquífero de Alter do Chão.

Tais dados levam a uma falsa sensação de comodidade. Sinalizam enganosamente que o problema de abastecimento de água está equacionado dentro das fronteiras brasileiras. Este pensamento está longe de ser verdade. Os recursos hídricos estão, em relação à população, mal distribuídos ao longo do Brasil. De longa data vem o problema da seca no Nordeste, trazendo baixos níveis de qualidade de vida na região, fome,mortes e um histórico de movimentos migratórios maciços por todo o país.

A bacia Amazônica está situada na região de menor densidade demográfica do país, trazendo a perigosa sensação de recurso barato e abundante, para não dizer inesgotável. Novamente tem-se uma linha de pensamento não condizente com a realidade. Um dos caminhos mais rápidos para a escassez de recursos é acreditar que eles são inesgotáveis. $\mathrm{O}$ elevado nível de desmatamento com o conseqüente impacto no clima da região, aliado a padrões incertos de precipitação pluviométrica, vem trazendo sinais de alerta para a região, representados por secas pouco comuns na Amazônia brasileira.

Mesmo em regiões onde, aparentemente, não há problemas de abastecimento o mau gerenciamento traz graves problemas. O caso da região sudeste brasileira é emblemático, apesar de ter recursos hídricos consideráveis, o desperdício, a ocupação desordenada, o lançamento de poluentes nos cursos de agua tem levado a região a uma situação crítica.

$\mathrm{O}$ atual projeto paulista de transposição das águas do rio Paraíba do Sul tem trazido preocupações a segmentos da sociedade fluminense. O caso do Mar de Aral ilustra que projetos de desvio dos cursos dos rios podem trazer conseqüências catastróficas. Todos os seis entrevistados mostraram-se preocupados com o impacto que o projeto de São Paulo pode trazer sobre o nível do rio Paraíba do Sul e seus possíveis desdobramentos sociais, econômicos e ambientais, até porque trata-se do rio mais importante do estado do Rio de Janeiro, alimentando não só importantes cidades do interior, como a capital do estado e as cidades circunvizinhas.

A grande maioria dos entrevistados - cinco em seis - se mostrou contrária ao projeto, em parte porque não se mostra sustentável e em parte porque existe a sensação de que a situação criada é artificial e se deve ao uso desordenado dos recursos hídricos. Os entrevistados enunciaram outras opções para a solução do problema. Opções que não implicam no simples abandono de uma necessária reflexão sobre a forma de interação entre o homem e a natureza. Opções que não implicam em trazer possíveis impactos para povos que habitam outras regiões. Deve ser lembrado que o crescimento desordenado implicará, no futuro, na ausência de fontes de água alternativas. Os recursos só são abundantes para aqueles que preservam.

Contudo, tais idéias só podem nascer de um amplo debate na sociedade. Um debate onde as partes envolvidas possam externar suas preocupações e idéias. Um debate, que pela fala da maioria dos entrevistados ainda não aconteceu.

A água foi ao longo da história humana um dos principais elementos responsáveis pela sedentarização dos povos. Das margens dos rios Tigre e Eufrates nasceu a primeira das grandes civilizações da humanidade, demonstrando a óbvia importância da água para a vida dos seres vivos. A emissão de poluentes, o consumo desordenado e o desperdício parecem demonstrar que esta lição o homem já esqueceu. 


\section{REFERÊNCIAS}

AGEVAP. Relatório de Atividades 2009. Resende: AGEVAP, 2009.

ALVARENGA, Livia Alves; MARTINS, Maria Paulete Pereira; CUARTAS, Luz Adriana; PENTEADO, Vinicius Alves; ANDRADE, Alexandra. Estudo da qualidade e quantidade da água em microbacia, afluente do rio Paraíba do Sul - São Paulo, após ações de preservação ambiental. Ambi-Agua, 7 (3): 228-240, 2012.

ANDRADE, Maria Margarida de. Como Preparar Trabalhos para Cursos de PósGraduação: Noções Práticas. São Paulo: Atlas, 1995.

BAVA, Silvio Caccia. A Falência de um Modelo de Gestão. Le Monde Diplomatique Brasil, 7 (82): 3, mai/2014.

BRANDÃO, Túlio. As Aberrações do Fundo do Rio Paraíba do Sul. O Globo, 79 (25.816): 16,12 de abril de 2004.

CANDIANI, Giovano;PENTEADO, Claudio Luis de Camargo;CENDRETTI, Elisângela Cristina;SANTOS,Eliane Melo dos;BIONDI, Ana Elisa Chicarino. Estudo de caso: aspectos socioambientais da pequena central hidrelétrica (PCH)-Queluz-SP, na bacia do rio Paraiba do Sul.Revista do Departamento de Geografia - USP, (25): 98-119, 2013.

CDP. Conexão Entre Mudanças Climáticas e Modelos de Negócios: Uma Agenda em Evolução. Relatório de Pesquisa, out/2014.

CEIVAP. Controle de Cheias na Bacia do Paraíba do Sul é Tema de Reunião. Informativo Pelas Águas do Paraíba, 11 (21): 9-11, maio de 2010.

CEIVAP. Projeto Desperta Preocupação nos Comitês de Bacias. Revista Pelas Águas do Paraíba, 4 (4): 10-11, janeiro de 2010.

COELHO, Victor. Paraíba do Sul: Um Rio Estratégico. Rio de Janeiro: Casa da Palavra, 2012.

FORNARI, Ernani. Dicionário Prático de Ecologia. São Paulo: Aquariana, 2001.

FUJIHARA, Marco Antonio; CAVALCANTI, Roberto; GUIMARÃES, André; GARLIPP, Rubens. O Valor das Florestas. São Paulo: Terra das Artes Editora, 2009.

GLANTZ, Michael H.; FIGUEROA, Robert M. Does the Aral Sea Merit Heritage Status?. Global Environmental Change, 7 (4): 357-380, December 1997.

GORE, Al. Our Choice: A Plan to Solve the Climate Crisis. Londres: Rodale, 2009.

KERGOMARD, Claude. Água (Recurso). In: VEYRET, Yvette (Org.). Dicionário do Meio Ambiente. São Paulo: Editora Senac, 2012.

KUMAR, Rama Sampath. A Tragédia Ecológica do Mar de Aral. Disponível em: <http://resistir.info/asia/mar_de_aral.html>. Acesso em: 2 jun. 2010.

LAKATOS, Eva Maria; MARCONI, Marina de Andrade. Metodologia do Trabalho Científico. São Paulo: Atlas, 1992.

LIEUTAGHI, Pierre. Árvores: A Essência da Vida em Suas Múltiplas Formas. São Paulo: Publifolha, 2012.

LUTTI, José Eduardo Ismael. Crise de Abastecimento era uma Tragédia Anunciada. Le Monde Diplomatique Brasil, 7 (82): 6, mai/2014. 
MACEDO, Guilherme Rocha; PIMENTEL, Ruderico Ferraz. Conflito e Integração na Transposição de Águas do Rio Paraíba do Sul para o Guandu. Disponível em: http://www.producao.uff.br/conteudo/rpep/volume42004/RelPesq_V4_2004_02.pdf. Acesso em: 22 mai. 2010.

MARTINS, Rosilda Baron. Metodologia Científica: Como tornar mais agradável a elaboração de trabalhos acadêmicos. Curitiba: Juruá, 2006.

MATTES, Delmar; TAGNIN, Renato; PRATA, José. A Crise é Maior que a Chuva. Le Monde Diplomatique Brasil, 7 (82): 4-5, mai/2014.

NASSER, Reginaldo. Um Velho Conhecido em Nova Roupagem. Caros Amigos, 19 (82): 22-27, set/2016.

NIEMEYER, Mark. Água: A Essência da Vida em Suas Múltiplas Formas. São Paulo: Publifolha, 2012.

OECO. A Morte do Mar de Aral. Disponível em: <http://www.oeco.com.br/ multimidia/geonoticias/21734-evaporacao-do-mar-de-aral>. Acesso em: 20 mai. 2010.

OREXCA. The History of the Aral Sea. Disponível em:

<http://www.orexca.com/aral_sea.shtml>. Acesso em: 20 jun. 2010.

PÁDUA, José Augusto. Um Sopro de Destruição: Pensamento Político e Crítica Ambiental no Brasil Escravista (1786-1888). Rio de Janeiro: Jorge Zahar Editor, 2002.

PHILLIPS, Dee. Atlas Mundial. São Paulo: Escala, 2010.

POLLACK, Henry. Um Mundo Sem Gelo. São Paulo: Rosari, 2011.

PORTO-GONÇALVES, Carlos Walter. Água. In: SADER, Emir et

al.(Coord.)Latinoamericana: Enciclopédia Contemporânea da América Latina e do Caribe. São Paulo: Boitempo; Rio de Janeiro: Laboratório de Políticas Públicas da UERJ, 2006.

RAUPP, Fabiano Maury; BEUREN, Ilse Maria. Metodologia da Pesquisa Aplicável às Ciências Sociais. In: BEUREN, I.M. (Org.). Como Elaborar Trabalhos Monográficos em Contabilidade: Teoria e Prática. São Paulo: Atlas, 2003.

RIBEIRO, Wagner Costa. Aquífero Guarani: gestão compartilhada e soberania. Estudos Avançados, 22 (64): 227-238, 2008.

RODRIGUES, Lúcia. A Nova Commodity. Caros Amigos, 19 (82): 20-21, set/2016.

SALGADO, Carla Maciel. Precipicitação e Enchentes no Município de São Gonçalo (RJ): Caracterização e Prevenção. In: SANTOS, Marcelo Guerra (Org.). Estudos Ambientais em Regiões Metropolitanas: São Gonçalo. Rio de Janeiro: EDUERJ, 2012.

THEOHARIS, Mark. Agricultura. In: ARP, Robert. 1001 Ideias que Mudaram Nossa Forma de Pensar. Rio de Janeiro: Sextante, 2014.

VILLAR, Pilar Carolina; RIBEIRO, Wagner Costa. Sociedade e gestão do risco: o aquífero Guarani em Ribeirão Preto-SP, Brasil. Revista de Geografia Norte Grande, 43: 51-64, 2009. 